\title{
Molecular tectonics: from crystals to crystals of crystals
}

\author{
Gabriela Marinescu, ${ }^{\text {a,b }}$ Sylvie Ferlay, ${ }^{\text {bb }}$ Nathalie Kyritsakas ${ }^{\mathrm{b}}$ and Mir Wais Hosseini ${ }^{* b}$ \\ Received (in XXX, XXX) Xth XXXXXXXXX 20XX, Accepted Xth XXXXXXXXX 20XX \\ DOI: $10.1039 / b 000000 x$
}

\section{${ }_{5}$ The in situ combination of $\mathrm{M}^{\mathrm{II}}$ cations $(\mathrm{Co}, \mathrm{Ni}, \mathrm{Cu}$ or $\mathrm{Zn})$ with 2,4,6-pyridinetricarboxylic acid as ligand, a bisamidinium dication as a H-bond donor tecton and $\mathrm{NaOH}$ leads to the formation anionic metal complexes $\mathrm{ML}_{2}{ }^{2-}$ and their interconnection into isomorphous 3D H-bonded networks \\ ${ }_{10}$ displaying different colours which were used as preformed seed crystals for the formation of crystals of crystals by 3D epitaxial growth.}

The design of hierarchically constructed molecular hyperstructures in the crystalline phase displaying at least two 15 different interconnected periodic domains is of prime importance for the development of task specific materials and devices. The molecular tectonics approach, ${ }^{1}$ dealing generation and analysis of extended architectures possessing translational symmetry in the crystalline phase, is a viable strategy for the design of infinite 20 periodic molecular networks resulting from mutual bridging between complementary tectons. ${ }^{2}$ The packing of molecular networks ${ }^{3}$ possessing 1-3D dimensionality leads to the generation of the crystalline material. For this approach, molecular crystals, considered as supramolecular entities, ${ }^{4}$ are analysed as periodic 25 molecular networks possessing translational symmetry. Among many possible reversible intermolecular attractive forces, the combination of directional hydrogen bonding with electrostatic charge-charge interactions ${ }^{5}$ is of particular interest for the design of molecular networks in the crystalline phase. ${ }^{6}$ Using cyclic 30 bisamidinium cations as $\mathrm{H}$-bond donor entities, a variety of molecular networks has been designed and generated in the presence of anionic units such as dicarboxylate, ${ }^{7,8}$ and polycyanometallates. ${ }^{9}$ This strategy was also employed for the formation of luminescent $t^{10}$ or porous ${ }^{11}$ crystals and of liquid 35 crystals. $^{12}$ Furthermore, following the same approach, the generation of crystals of crystals resulting from 3D epitaxial growth of crystalline layers on preformed seed crystals using dicationic organic tectons and polycyanometallates was demonstrated. ${ }^{133_{14}+15}$ Few other examples of crystals of crystals 40 based on H-bonding have been also reported. ${ }^{16}$ More recently few other related cases based on either coordination complexes ${ }^{17}$ or on coordination polymers ${ }^{18}$ have been published. This type of hierarchical architectures, owing to their low density, transparency, variability of refractive index, may present 45 interesting optical properties."

Here we report on the generation of crystals of crystals resulting from the $3 \mathrm{D}$ epitaxial growth of crystalline layers on preformed crystals using combinations of transition metal anionic complexes of different colours with a dicationic H-bond donor 50 tecton.

The followed rational was based on the formation of neutral $\mathrm{H}$ bonded networks resulting from combinations of the dicationic tecton $\mathbf{1}^{2+}$ displaying four $\mathrm{H}$-bond donor sites oriented in a divergent fashion with dianionic isomorphous octahedral metal
${ }_{55}$ complexes $\left[\mathrm{ML}_{2}\right]^{2-}$ offering four anionic H-bond acceptor sites located in the vicinity of the metal centre (Fig. 1). It is worth noting that, owing to the distance $\left(\mathrm{d}_{\mathrm{N}-\mathrm{N}}\right.$ of $\left.c a 7.21 \AA\right)$ between two H-bond donor sites located on the same face of the organic molecule, imposed by the use of the phenyl unit as spacer 60 connecting the two cyclic amidinium moieties, the tecton $\mathbf{1}^{2+}$ may only interact with anionic partners through a tetrakis monohapto mode. Dealing with the $\left[\mathrm{ML}_{2}\right]^{2-}$ complex, in order to generate crystals displaying different colours, $\mathrm{Co}(\mathrm{II}), \mathrm{Cu}(\mathrm{II}), \mathrm{Ni}(\mathrm{II})$ and $\mathrm{Zn}$ (II) metals cations were combined with the doubly ${ }_{65}$ deprotonated form (L) of 2,4,6-pyridinetricarboxylic acid. ${ }^{20}$ This type of complex has been also used for the formation coordination polymers. ${ }^{21}$

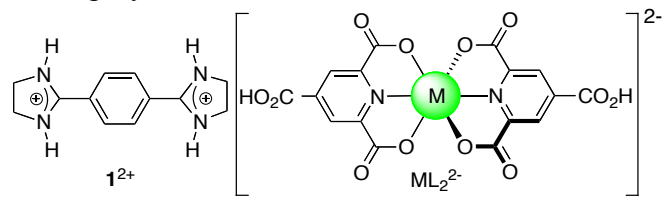

Figure 1: Representation of the tetra H-bond donor dicationic 70 bisamidinium $\mathbf{1}^{2+}$ and dianionic H-bond acceptor isomorphous complexes $\left[\mathrm{ML}_{2}\right]^{2-}(\mathrm{M}=\mathrm{Co}, \mathrm{Cu}, \mathrm{Ni}, \mathrm{Zn})$.

The generation of H-bonded networks based on combinations of the H-bond donor dicationic bisamidinium $\mathbf{1}^{2+}$ and isomorphous dianionic H-bond acceptor complexes $\left[\mathrm{ML}_{2}\right]^{2-}(\mathrm{M}=$ ${ }_{75} \mathrm{Co}, \mathrm{Cu}, \mathrm{Ni}, \mathrm{Zn}$ ) may be achieved in two different manners: i) the synthesis of $\left[\mathrm{ML}_{2}\right]^{2-}(\mathrm{M}=\mathrm{Co}, \mathrm{Cu}, \mathrm{Ni}, \mathrm{Zn})$ complexes as, for example, their alkaline salts and their subsequent combination with the bisamidinium $\mathbf{1}^{2+}$ as its chloride or tosylate salt, or ii) a one-pot procedure based on the combination of 2,4,680 pyridinetricarboxylic acid as the ligand, the desired metal cation in the oxidation state II $(\mathrm{Co}, \mathrm{Ni}, \mathrm{Cu}, \mathrm{Zn})$, the bisamidinium dication $\mathbf{1}^{2+}$ and a base to deprotonate the acid. For this approach, both the anionic metal complex and its subsequent organisation into networks by interaction with the cationic tecton $\mathbf{1}^{2+}$ are 85 achieved in situ. The latter strategy was adopted. The metal centres were used as their chloride or nitrate salts. The counter ion of $\mathbf{1}^{2+}$ was chloride anion and the base used was $\mathrm{NaOH}$. The reaction was performed at $50{ }^{\circ} \mathrm{C}$ in a 9:1 mixture of $\mathrm{H}_{2} \mathrm{O} / \mathrm{DMSO}$

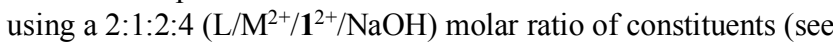
90 experimental section in ESI). A series of four crystals $\left(\left[\mathrm{M}\left(\mathrm{C}_{8} \mathrm{H}_{3} \mathrm{NO}_{6}\right)_{2}\right]\left[\mathrm{C}_{12} \mathrm{H}_{16} \mathrm{~N}_{4}\right] \cdot 4 \mathrm{H}_{2} \mathrm{O}(\mathrm{M}=\mathrm{Co}, \mathrm{Ni}, \mathrm{Cu}, \mathrm{Zn})\right)$ have been obtained (Fig. 2) and were, in addition to elemental analysis and IR spectroscopy, structurally characterised by both X-ray diffraction on single crystals (Table T1, ESI) and on powder (Fig. $\left.{ }_{95} \mathrm{~S} 1, \mathrm{ESI}\right)$.

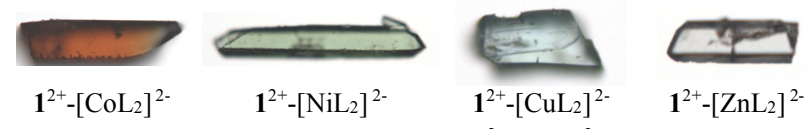

Figure 2: Pictures of crystals formed by $\mathbf{1}^{2+}-\left[\mathrm{ML}_{2}\right]^{2-}(\mathrm{M}=\mathrm{Co}$ (orange), $\mathrm{Ni}$ (light green), $\mathrm{Cu}$ (light blue) and $\mathrm{Zn}$ (colourless)). 
Owing to the isomorphous character of all four crystalline materials, only a detailed structural analysis of $\mathbf{1}^{2+}-\left[\mathrm{CoL}_{2}\right]^{2-}$ is given below.

The crystal, in addition to $\mathbf{1}^{2+}$, $\mathrm{Co}(\mathrm{II})$ cation, anionic ligand $\mathrm{L}^{2-}$, 5 contains water molecules. The Co atom lies on a twofold axis and the cation lies about an inversion centre at the centre of the sixmembered ring. The bisamidinium dication is not planar but tilted with an average torsion angle between the phenyl spacer and the 5 members cyclic amidinium moiety of $c a 15^{\circ}$. The metal cation, 10 forming a mononuclear $\mathrm{ML}_{2}$ type complex, is surrounded by $4 \mathrm{O}$ and $2 \mathrm{~N}$ atoms and adopts a deformed octahedral coordination geometry (for angles and distances see Table 2, ESI ) with average $\mathrm{d}_{\mathrm{O}-\mathrm{Co}}$ and $\mathrm{d}_{\mathrm{N}-\mathrm{Co}}$ of 2.15 and $2.00 \AA$ respectively. The square base of the octahedron is occupied by four $\mathrm{O}$ atoms 15 belonging to four carboxylate moieties, whereas the two apical positions are occupied by two $\mathrm{N}$ atoms of two anionic $\mathrm{L}^{2-}$. Both carboxy group located at position 4 of the ligands remain protonated and do not participate in the binding of the metal cation. Each dicationic tecton $\mathbf{1}^{2+}$ is surrounded by four different 20 anionic complexes (Fig. 3 top left) and each anion is surrounded by four tectons $\mathbf{1}^{2+}$ (Fig. 3 top right). The latter behaves as a tetrakis H-bond donor. The interconnection between the anionic and cationic partners takes place through $\mathrm{H}$-bonds in the tetramonohapto mode between the $\mathrm{H}$ atoms of the bisamidinium 25 tecton and both coordinating and non-coordinating $\mathrm{O}$ atom of the carboxylate moieties of the $\left[\mathrm{CoL}_{2}\right]^{2-}$ with an average $\mathrm{N}-\mathrm{O}$ distance of $2.82 \AA$. The water molecules are $\mathrm{H}$-bonded either with the $\mathrm{O}$ atoms of the carboxylate moieties not engaged in the binding of metal cations ( $\mathrm{d}_{\mathrm{O}-\mathrm{O}}$ of 2.71 and $2.92 \AA$ ) or to the $\mathrm{O}$ 30 atoms of the carboxylic units $\left(\mathrm{d}_{\mathrm{O}-\mathrm{O}}=2.56 \AA\right)$.

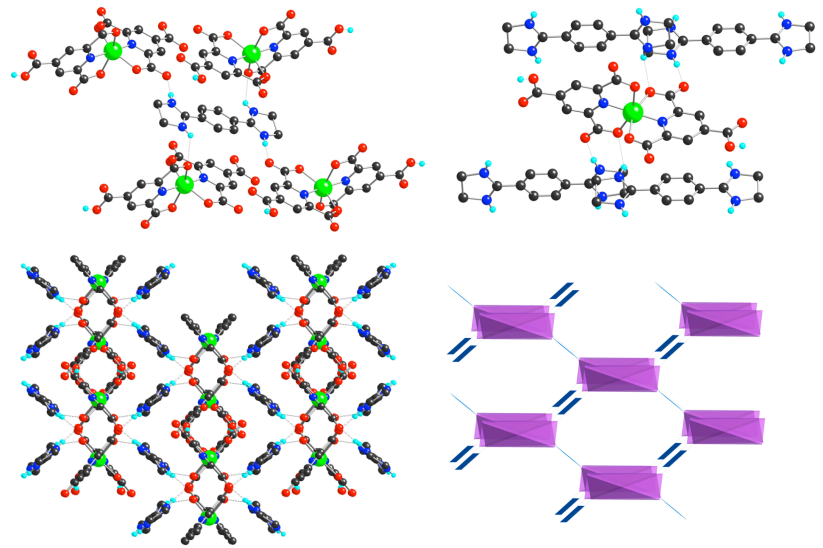

Figure 3: A portion of the crystal structure of $\mathbf{1}^{2+}-\left[\mathrm{CoL}_{2}\right]^{2-}$ showing the surrounding of the organic tecton (top left), of the anionic complex (top right), the overall 3-D diamondoid H-bonded network (bottom left) and its simplified polyhedral representation (bottom right). $\mathrm{H}_{2} \mathrm{O}$ molecules 35 and $\mathrm{H}$ atoms, except those involved in $\mathrm{H}$-bonds, are not presented for clarity. For bond distances and angles see text and ESI.

The overall structure, when taking into account all H-bonds between the anionic and cationic partners, is a deformed 3D diamondoid network (Fig. 3 bottom left). This topology results 40 from the interconnection through $\mathrm{H}$ bonds of tetrahedral coordination units by rectangular organic connectors (Fig. 3 bottom right). The average distance between metallic centres within the network is $9.64 \AA$ which corresponds to the value of the $b$ parameter. Owing to the presence of axial carboxylic groups 45 at the position 4 on the pyridyl units in the cavities, the diamondoid-like network is not porous.

The purity of all four polycrystalline materials was established by XRPD (Fig. 4). The latter further confirmed the isomorphous nature of all four crystals. It is worth noting that all four crystals ${ }_{50}$ are perfectly stable outside the crystallisation solvent system. No loss of crystallinity was observed after several years.

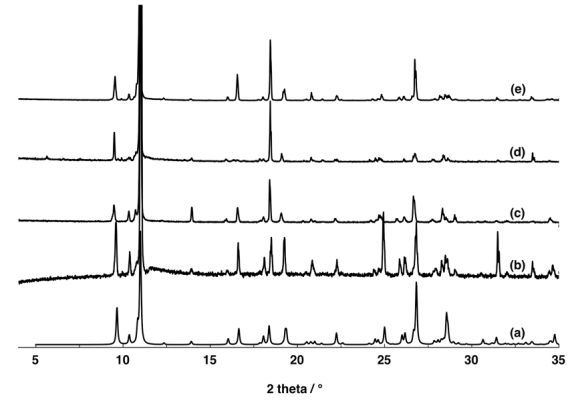

Figure 4: Comparison of the simulated and observed PXRD patterns: simulated for $\mathbf{1}^{2+}-\left[\mathrm{CoL}_{2}\right]^{2-}(\mathrm{a})$, recorded for $\mathbf{1}^{2+}-\left[\mathrm{CoL}_{2}\right]^{2-}(\mathrm{b}), \mathbf{1}^{2+}-\left[\mathrm{NiL}_{2}\right]^{2-}$ 55 (c), $\mathbf{1}^{2+}-\left[\mathrm{CuL}_{2}\right]^{2-}(\mathrm{d}), \mathbf{1}^{2+}-\left[\mathrm{ZnL}_{2}\right]^{2-}(\mathrm{e})$.

The synthesis of four robust isomorphous crystals with differentiated colours resulting from the use of different transition metals (Fig. 2) and the nature of the interconnection between the anionic and cationic tectons by reversible and flexible charge 60 assisted H-bonds, prompted us to use combinations of these systems for the formation of crystals of crystals by $3 \mathrm{D}$ epitaxial growth. The latter process was achieved under the same condition as the one used for the preparation of crystals of the type $\mathbf{1}^{2+}$ $\left[\mathrm{M}_{1} \mathrm{~L}_{2}\right]^{2-}$ (see above and ESI) by immersing preformed crystals of ${ }_{65} \mathbf{1}^{2+}-\left[\mathrm{M}_{1} \mathrm{~L}_{2}\right]^{2-}(\mathrm{M} 1=\mathrm{Co}$ or $\mathrm{Ni})$ into a solution containing $\mathrm{M} 2\left(\mathrm{NO}_{3}\right)_{2}(\mathrm{M} 2=\mathrm{Ni}$ or $\mathrm{Zn})$, ligand $\mathrm{L}, \mathbf{1}^{2+}-2 \mathrm{Cl}^{-}$and $\mathrm{NaOH}$. The fabrication led to crystals of crystals of the type $\mathbf{1}^{2+}-\left[\mathrm{M}_{2} \mathrm{~L}_{2}\right]^{2-}$ (a) $\mathbf{1}^{2+}\left[\mathrm{M}_{1} \mathrm{~L}_{2}\right]^{2-}$ (see ESI). Three first generation of crystals of crystals, mainly $\mathbf{1}^{2+}-\left[\mathrm{ZnL}_{2}\right]^{2-} @ \mathbf{1}^{2+}-\left[\mathrm{NiL}_{2}\right]^{2-}, \mathbf{1}^{2+}-\left[\mathrm{ZnL}_{2}\right]^{2-@ 1 \mathbf{1}^{2+}-}$ $70\left[\mathrm{CoL}_{2}\right]^{2-}, \mathbf{1}^{2+}-\left[\mathrm{NiL}_{2}\right]^{2-} @ \mathbf{1}^{2+}-\left[\mathrm{CoL}_{2}\right]^{2-}$, have been generated (Fig. 5 $\mathrm{a}, \mathrm{b}$ and $\mathrm{c}$ respectively). The $3 \mathrm{D}$ epitaxial growth was operational owing to slight differences in the metrics of the unit cell parameters for all four crystalline systems (maximum deviation of $1.2 \%$ for $\mathbf{1}^{2+}-\left[\mathrm{ZnL}_{2}\right]^{2-} @ \mathbf{1}^{2+}-\left[\mathrm{NiL}_{2}\right]^{2-}, 0.2 \%$ for $\mathbf{1}^{2+}-\left[\mathrm{ZnL}_{2}\right]^{2-}$ $75 @ \mathbf{1}^{2+}-\left[\mathrm{CoL}_{2}\right]^{2-}$, and $0.2 \%$ for $\mathbf{1}^{2+}-\left[\mathrm{NiL}_{2}\right]^{2-} @ \mathbf{1}^{2+}-\left[\mathrm{CoL}_{2}\right]^{2-}$ ) (see tables T1\&T3, ESI).

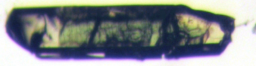

a

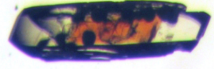

b

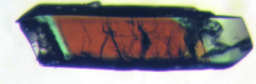

Figure 5 : Pictures of the $1^{\text {st }}$ generation of crystals of crystals of $\mathbf{1}^{2+}$ $\left[\mathrm{ZnL}_{2}\right]^{2-} @ 1^{2+}-\left[\mathrm{NiL}_{2}\right]^{2-}(\mathrm{a}), \mathbf{1}^{2+}-\left[\mathrm{ZnL}_{2}\right]^{2-} @ 1^{2+}-\left[\mathrm{CoL}_{2}\right]^{2-}(\mathrm{b}), \mathbf{1}^{2+}-\left[\mathrm{NiL}_{2}\right]^{2-}$ (a) $\mathbf{1}^{2+}-\left[\mathrm{CoL}_{2}\right]^{2-}(\mathrm{c})$

${ }_{80}$ The rectangular cuboid morphology of the seed crystals $\mathbf{1}^{2+}$ $\left[\mathrm{M}_{1} \mathrm{~L}_{2}\right]^{2-}(\mathrm{M} 1=\mathrm{Co}$ or Ni), indicate a face differentiated growth kinetics. For the first generation of all three crystals of crystals $\mathbf{1}^{2+}-\left[\mathrm{M} 2 \mathrm{~L}_{2}\right]^{2-} @ \mathbf{1}^{2+}-\left[\mathrm{M}_{1} \mathrm{~L}_{2}\right]^{2-}$, the same trend is observed. All three crystals of crystals have been characterised by $\mathrm{X}$ ray diffraction 85 on single crystals. For each system, the unit cell parameters were first determined (table T3, ESI). Then the crystal of crystal was cut and for each crystalline moiety corresponding to $\mathbf{1}^{2+}-\left[\mathrm{M}_{1} \mathrm{~L}_{2}\right]^{2-}$ and to $\mathbf{1}^{2+}-\left[\mathrm{M} 2 \mathrm{~L}_{2}\right]^{2-}$, the unit cell parameters were determined. In all cases, they were found to be identical to those observed for the 90 pure crystals. 
The diffraction study on crystals of crystals further revealed the conservation of the crystalline system (monoclinic) and the space group $(C 2 / c)$. Although crystals were not found to be twinned, for high theta values some twinned reflections resulting from the 5 slight difference in cell parameters between the crystalline

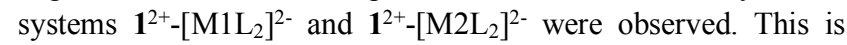
consistent with a $3 \mathrm{D}$ epitaxial growth process.

In conclusion, upon combining four transition metals in the same oxidation state II $(\mathrm{M}=\mathrm{Co}, \mathrm{Cu}, \mathrm{Ni}, \mathrm{Zn})$ with $2,4,6-$ 10 pyridinetricarboxylic acid, the bisamidinium organic tecton $\mathbf{1}^{2+}$ and $\mathrm{NaOH}$ as base, robust crystals of different colours composed of in situ generated $\left[\mathrm{ML}_{2}\right]^{2-}$ anionic complexes, $\mathbf{1}^{2+}$ and water molecules have been obtained. Within the crystal, the anionic and cationic partners are interconnected through charge assisted $\mathrm{H}$ 15 bonds leading to a deformed 3D diamondoid type architecture. All four crystals are isomorphous and their unit cell parameters differ slightly (less than $1.2 \%$ ). Using the preformed crystals as seeds, crystals of crystals of the type $\mathbf{1}^{2+}-\left[\mathrm{M} 2 \mathrm{~L}_{2}\right]^{2-} @ \mathbf{1}^{2+}-\left[\mathrm{M}_{1} \mathrm{~L}_{2}\right]^{2-}$ have been generated by $3 \mathrm{D}$ epitaxial growth processes. This study 20 offers some interesting perspectives in terms of engineering hierarchically constructed crystalline materials.

The study of the interface between the two crystalline zones by near field microscopy and extension to other combinations of transition anionic metal complexes with cationic organic tectons 25 are currently under investigation.

\section{Acknowledgements}

The University of Strasbourg, the CNRS, Institut Universitaire the France, the International Centre for Frontier Research in Chemistry (icFRC) are acknowledged for financial support.

\section{${ }_{30}$ Notes and references}

a Institute of Physical Chemistry, Splaiul Independentei 202, 060021, Bucharest, Romania

${ }^{b}$ Molecular Tectonic Laboratory, UMR UDS-CNRS 7140, icFRC, University of Strasbourg, Institut Le Bel, 4, rue Blaise Pascal, F-67000

35 Strasbourg,France.hosseini@unistra.fr,ferlay@unistra.fr

$\dagger$ Electronic Supplementary Information (ESI) available: Full experimental details and crystallographic tables T1-3. CCDC 949324949327. See DOI: 10.1039/b000000x/

40

[1] a) M. Simard, D. Su and J. D. Wuest, J. Am. Chem. Soc., 1991, 113, 4696, b) S. Mann, Nature, 1993, 365, 499, c) M. W. Hosseini, Acc. Chem. Res., 2005, 38, 313.

[2] a) J. D. Wuest, Chem. Commun., 2005, 5830, b) M. W. Hosseini, Chem. Commun., 2005, 582.

[3] W M. W. Hosseini, CrystEngComm., 2004, 6, 318.

[4] a) J. D. Dunitz, Pure Appl. Chem., 1991, 63, 177, b) J.-M. Lehn, Supramolecular Chemistry, Concepts and Perspectives, VCH, Weinheim, 1995.

[5] a) M.W. Hosseini, R. Ruppert, P. Schaeffer, A. De Cian, N. Kyritsakas, J. Fischer, Chem. Commun., 1994 2135, b) M. D.Ward, Chem. Commun., 2005, 5838.

[6] a) M. C. Etter, Acc. Chem. Res., 1990, 23, 120, b) G. R. Desiraju, Angew. Chem. Int. Ed. Engl., 1995, 34, 2311.

[7] O. Félix, M. W. Hosseini, A. De Cian, J. Fischer, New J. Chem., 1998, $22,1389$.

[8] a) M. W. Hosseini, Coord. Chem. Rev., 2003, 240, 157, b) O. Felix, M. W. Hosseini, A. De Cian, J . Fischer, Angew. Chem. Int. Natl. Ed. Engl. 1997, 36 102, c) O. Felix, M. W. Hosseini, A. De Cian, J.
Fischer, N. J. Chem., 1998, 22, 1389, d) O. Felix, M. W. Hosseini, A. De Cian, J. Fischer, J. Chem. Soc., Chem. Commun., 2000, 281.

[9] S. Ferlay and M. W. Hosseini Eds. P. Samorì and F. Cacialli, WileyVCH, 2011, pp 195-232.

[10] a) C. Parachiv, S. Ferlay, M. W. Hosseini, V. Bulach, J.-M. Planeix, Chem. Commun., 2004, 2270, b) P. Dechambenoit, S. Ferlay, N. Kyritsakas, M. W. Hosseini, CrystEngComm., 2011, 13, 1922.

[11] a) S. Ferlay, O. Félix, M. W. Hosseini, J.-M. Planeix, N. Kyritsakas, Chem. Commun., 2002, 702, b) P. Dechambenoit, S. Ferlay, N. Kyritsakas, M. W. Hosseini, J. Am. Chem. Soc., 2008, 130, 17106, c) P. Dechambenoit, S. Ferlay, M. W. Hosseini, J.-M. Planeix, N. Kyritsakas, New.J. Chem., 2006, 30, 1403.

[12] P. Dechambenoit, S. Ferlay, B. Donnio, D. Guillon, M. W. Hosseini, Chem. Commun., 2011, 47, 734.

[13] a) S. Ferlay, M. W. Hosseini, Chem. Commun., 2004, 788, b) P. Dechambenoit, S. Ferlay, M. W. Hosseini, Cryst. Gr. Des., 2005, 5 , 2310 , c) P. Dechambenoit, S. Ferlay, N. Kyritsakas, M. W. Hosseini, Chem. Commun., 2009, 1559.

[14]E. F. Brès, S. Ferlay, P. Dechambenoit, H. Leroux, M. W. Hosseini, S. Reyntjens, J. Mat. Chem., 2007, 1559.

[15] B. K. Olmsted, S. Ferlay, P. Dechambenoit, M. W. Hosseini, M. D. Ward, Cryst. Growth \& Design., 2009, 6, 2841.

[16] a) J. C. MacDonald, P. C. Dorrestein, M. M. Pilley, M. M. Foote, J. L. Lundburg, R. W. Henning, A. J. Schultz and J. L. Manson, J. Am. Chem. Soc., 2000, 122, 11692, b) J. C. Noveron, M. S. Lah, R. E. Del Sesto, A. M. Arif, J. S. Miller and P. J. Stang, J. Am. Chem. Soc., 2002, 124, 6613, c) T.-J. M. Luo, J. C. MacDonald and G. T. R. Palmore, Chem. Mater., 2004, 16, 4916, d) K. Sada, K. Inoue, T. Tanaka, A. Epergyes, A. Tanaka, N. Tohnai, A. Matsumoto, M. Miyata, Angew. Chem. Int. Ed. 2005, 44, 7059.

[17] J. W. Steed, A. E. Goeta, J. Lipkowski, D. Swierczynski, V. Panteleon, S. Handad, Chem. Commun., 2007, 813.

[18] a) K. Koh, A. G. Wong-Foy, A. J. Matzger, Chem. Commun., 2009, 6162, b) S. Furukawa, K. Hirai, K. Nakagawa, Y. Takashima, R. Matsuda, T. Tsuruoka, M. Kondo, R. Haruki, D. Tanaka, H. Sakamoto, S. Shimomura, O. Sakata and S. Kitagawa, Angew. Chem., Int. Ed., 2009, 48, 1766, c) K. Hirai, S. Furukawa, M. Kondo, H. Uehara, O. Sakata, S. Kitagawa, Angew. Chem. Int. Ed., 2011, 50, 8057, (d) K. Hirai, S. Furukawa, M. Kondo, M. Meilikhov, Y. Sakata, O. Sakata, S. Kitagawa, Chem. Commun., 2012, 48, 6472.

[19] (a) J. D. Wright, Molecular Crystals; Cambridge University Press: New York, 1995, (b) S. J. Bonafe, M. D. Ward, J. Am. Chem. Soc., 1995, 117, 7853, (c) R. D. Bailey, L. L. Hook, A. K. Powers, T. W. Hanks and W. T. Pennington, Cryst. Eng. 1998, 1, (d) C. A. Mitchell, L. Yu, M. D. Ward, J. Am. Chem. Soc., 2001, 123, 10830, (e) J. Fraxedas, Adv. Mater. 2002, 14, 1603.

[20] L. C. Nathan, D. C. Zapien, A. M. Mooring, C. A. Doyle, J. A. Brown Polyhedron, 1989, 8, 745.

[21] (a) S. K. Ghosh, G. Savitha, P. K. Bharadwaj, Inorg. Chem., 2004 43, 5495, (b) S. K. Ghosh and P. K. Bharadwaj, Inorg. Chem., 2004, 43, 6887, (c) R. P. Houser, D. Cheng, Acta Cryst., 2005, E 61, 1649 , (d) S. K. Ghosh and P. K. Bharadwaj J. Chem. Sci., 2005, 117, 23, (e) H-L. Gao, B. Ding, L. Yi, P. Cheng, D-Z. Liao, S-P. Yan, Z-H. Jiang, Inorg. Chem. Comm., 2005, 8, 151, (f) S. K. Ghosh, M. S. El Fallah, J. Ribas, P. K. Bharadwaj, Inorg. Chim. Acta, 2006, 359, 468, (g) M. V. Yigit, K. Biyikli, B. Moulton, J. C. MacDonald, Cryst. Growth Des., 2006, 6, 6, (h) H-L. Gao, L. Yi, B. Ding, H-S. Wang, P. Cheng, D-Z. Liao, S-P. Yan, Inorg. Chem. 2006, 45, 481. 